\title{
Detección por medio de la técnica RT-PCR de los virus CymMV y ORSV en el cultivo de orquídeas
}

\author{
Paulina G. Villena Ochoa \\ Facultad de Ciencias Agropecuarias, Universidad de Cuenca, Cuenca, Ecuador. \\ Autor para correspondencia: paulina.villena@ucuenca.edu.ec \\ Fecha de recepción: 7 de marzo 2013 - Fecha de aceptación: 21 de junio 2013
}

\begin{abstract}
RESUMEN
El Cymbidium mosaic potexvirus (CymMV) y Odontoglossum ringspot tobamovirus (ORSV), constituyen dos de los virus más prevalecientes y económicamente importantes en el cultivo de orquídeas. Ambos virus han ocasionado incalculables pérdidas a los cultivadores, convirtiéndose en patógenos severos que reducen el vigor de la planta, calidad de las flores y lo que es peor no pueden ser controlados por ningún método. El método de diagnóstico basado en la reacción en cadena de la polimerasa con transcripción reversa (RT-PCR) fue aplicado en la presente investigación para la detección de CymMV y ORSV. Se realizó un estudio comparativo mediante la realización de pruebas serológicas (método ELISA) y RT-PCR, con los resultados se pudo certificar plantas libres de virus a través de la selección de meristemos destinados a la micro-propagación y obtención de plantas sanas. Se evaluaron muestras de hojas, flores, bulbos y plántulas reproducidas in vitro de distintas especies de Catleya de plantas saludables o con señales clínicas de infección. Los ensayos se realizaron en Laboratorio de Biotecnología Molecular de la Empresa Concepto Azul SA en Guayaquil, Ecuador. Los resultados obtenidos mostraron que la técnica de RT-PCR aplicada al diagnóstico de ambos virus es más sensible que el ELISA. Por lo cual, la RT-PCR fue más eficiente para detectar infecciones por CymMV y ORSV. El CymMV fue detectado preferencialmente en hojas, flores y en menor grado en bulbos, mientras que el ORSV solo fue detectado en hojas y bulbos, pero no en flores. Esto condujo a describir sintomatologías asociadas con cada tipo de infección.
\end{abstract}

Palabras clave: Cymbidium mosaic potexvirus (CymMV), Odontoglossum ringspot tobamovirus (ORSV), RT-PCR, ELISA.

\begin{abstract}
Cymbidium mosaic potexvirus (CymMV) and Odontoglossum ringspot tobamovirus (ORSV) are the most prevalent pathogens affecting worldwide the cultivation of orchids, causing incalculable losses in revenue. They reduce growth vigor and quality, and what is most problematic they are not curable once infected. A diagnostic method, based on the chain reaction reverse transcription polymerase (RTPCR), was developed to detect both viruses. The method consists of the extraction of nucleic acids of infected plants and applying the RT-PCT method, similar to the ELISA (enzyme linked immunosorbent assay) virus indexing technique. Leave, flower and bulb samples of different species of in vitro reproduced healthy and affected Cattleya orchids were analyzed in the molecular biotechnology laboratory of Concept Blue Corporation in Guayaquil, Ecuador. The comparative analysis revealed that RT-PCR is more effective in the detection of CymMV and ORSV viruses than the ELISA technique. Furthermore the study revealed that CymMV was preferentially detected in leaves, flowers and small bulbs, while the ORSV virus was only detected in leaves and bulbs. The latter permitted to describe the symptoms associated to each type of infection and the propagation of virus-free plants applying the meristem-tip culture.
\end{abstract}

Keywords: Cymbidium mosaic potexvirus (CymMV) and Odontoglossum ringspot tobamovirus, RTPCR, ELISA. 


\section{INTRODUCCIÓN}

Actualmente las orquídeas se constituyen en uno de los principales cultivos ornamentales gracias a la belleza y exoticidad de sus flores. Ecuador es el segundo país en el mundo en términos de cantidad de especies de orquídeas. La mayoría de cultivos de orquídeas son afectados por enfermedades virales. Más de 50 virus han sido reportados que afectan a este cultivo (Chang y col., 2004); sin embargo, Cymbidium mosaic potexvirus (CymMV) y Odontoglossum ringspot tobamovirus (ORSV) son los dos virus más prevalecientes y económicamente importantes. Ambos tipos de virus reducen el vigor de la planta, rango de crecimiento y calidad de las flores (Wong y col., 1996; Navalinskienë1 y col., 2005). Las infecciones virales debilitan las plantas haciéndolas más susceptibles a otras formas de daño; dos de los efectos más notables son el amarillamiento (clorosis) por inhibición de la formación de cloroplastos y muerte de tejidos (necrosis).

Debido a la diversidad genética de orquidáceas, la observación de señales clínicas de CymMV es altamente variable y no puede ser considerada como base de diagnóstico. Frecuentemente huéspedes tolerantes han sido contaminados con CymMV y no presentan síntomas. Por tanto el número de plantas infectadas pueden inconcientemente ser multiplicadas por propagación vegetativa (Vejaratpimol y col., 1998). Orquídeas infectadas con CymMV pueden mostrar varias señales clínicas tales como: enanismo, estriado clorótico a puntos negros o patrones de líneas necróticas con parches hundidos, deformación en las flores en algunas especies importantes como Cattleya y Dendrobium; hojas con mosaicos, manchas necróticas, brotes enroscados y hojas con estriamientos cloróticos (Vejaratpimol, 1998). El virus ORSV produce puntos cloróticos o necróticos, estriados y anillos a nivel foliar (Lawson y Hsu, 1995). Lesiones hendidas cloróticas o necróticas en hojas y descoloramientos en flores (Zettler y col., 1990). La Biotecnología molecular se ha convertido en una vía útil que permit identificar virus de una manera rápida, efectiva, confiable mediante la implementación de metodologías de diagnóstico eficientes.

La reacción en cadena polimerasa (PCR) es una herramienta poderosa para amplificar pequeñas cantidades de ADN para varios análisis moleculares. La combinación de la reversa trascripción (RT) con subsecuentes amplificaciones por PCR (RT-PCR) ha sido usada en el diagnóstico de distintos virus con genoma ácido ribonucleico (ARN) (De Blas, 1994; Bateson y Dale, 1995).

\section{MATERIALES Y MÉTODOS}

La investigación se llevó a cabo en 5 etapas:

1. Evaluación de los iniciadores seleccionados para detección de los virus CymMV y ORSV.

2. Análisis de muestras sintomáticas y asintomáticas mediante PCR y ELISA en la que se evaluó la capacidad de detección por ambas técnicas.

3. Evaluación de material micropropagado de plantas infectadas con CymMV, con el propósito de indexación del nuevo material vegetativo obtenido.

4. Análisis comparativo de los resultados de RT-PCR y ELISA.

5. Evaluación a insectos posibles vectores de virus.

Las muestras se recolectaron en el campo (Plantaciones Tosi Cuenca, Plantaciones Ecuagenera, Gualaceo) un día anterior al análisis en laboratorio. Se recolectaron muestras de hojas, de flores, pseudobulbos de plantas que presentaron señales clínicas de enfermedad. Para la detección de CymMV y ORSV mediante la Técnica de RT-PCR; se utilizaron primers específicos proveídos por IDT (Integrated DNA Technologies, Inc.) y siguiendo protocolos de extracción de ARN. Los primers o iniciadores se seleccionaron mediante el Programa Vector NTI Advance ${ }^{\circledR}$ 11.5. Los iniciadores nos permitieron la amplificación de la región del gen que codifica para cápside con la obtención de un producto de $757 \mathrm{pb}$ para el CymMV y otro producto de $477 \mathrm{pb}$ para ORSV. Las secuencias utilizadas se describen en la Tabla 1. 
Tabla 1. Las secuencias de CymMV y ORSV.

Para Cymbidium mosaic virus

Secuencia CymMV CPFw

5'-TAG CTA TAG GCC CCT GGC -3'

Secuencia CymMV CPRev

5'-CTT TAG AAA ACC ACA CGC -3'
Para Odontoglossum ringspot virus

Secuencia OCP u ORSV Fw

5'-ATG TCT TAC ACT ATT ACA GAC C -3'

Secuencia OCP u ORSV Rev

5'-TTA GGA AGA GGT CCA AGT AAG -3'

La retrotranscripción cuyo principio indica que la enzima transcriptasa inversa utiliza el ARN como molde para sintetizar una cadena complementaria de DNA de allí el nombre de ADNc (complementario), en el presente estudio se utilizó la enzima reverse transcriptasa M-MLV RT buffer. Para la amplificación de CymMV y ORSV se evaluó los protocolos de amplificación (Tabla 2).

Tabla 2. Protocolos de amplificación.

\begin{tabular}{lcc}
\hline \multicolumn{1}{c}{ Ciclo } & CymMV & ORSV \\
\hline 1 ciclo & Desnaturalización: $94^{\circ} \mathrm{C}$ por min & Desnaturalización: $94^{\circ} \mathrm{C}$ por 5 min \\
\hline \multirow{2}{*}{40 ciclos } & Desnaturalización: $94^{\circ} \mathrm{C}$ por 30 seg \\
& Hibridación: 50,52 o $55^{\circ} \mathrm{C}$ por 45 seg & Hibridación: $50^{\circ} \mathrm{C}$ por 45 seg. \\
& Polimerización: $72^{\circ} \mathrm{C}$ por 45 seg \\
\hline \multirow{2}{*}{1 ciclo } & Polimerización: $72^{\circ} \mathrm{C}$ por 10 min \\
& $4^{\circ} \mathrm{C}$ para su conservación \\
\hline
\end{tabular}

La temperatura de hibridación es variable depende de la temperatura de fusión ( $\mathrm{T}_{\text {Fusión }}$ ) de los primers del virus $\left(+0-5^{\circ} \mathrm{C}\right.$ de la $\left.\mathrm{T}_{\text {Fusión }}\right)$. Para el análisis de resultados por RT-PCR se realizó migración por electroforesis horizontal a 100 Volts durante 30 minutos en geles de agarosa, preparar al $1,5 \%$ en buffer TAE $1 \mathrm{X}$, con un MPM de $100 \mathrm{~Kb}$ y visualización de los fragmentos amplificados en los geles teñidos con Bromuro de Etídio $\left(0,5 \mathrm{mg} \mathrm{ml}^{-1}\right)$ en un transiluminador TFX-20M.

Para la detección de virus por la técnica de ELISA (acrónimo del inglés Enzyme-Linked ImmunoSorbent Assay, Ensayo por inmunoabsorción ligado a enzimas) se siguió el protocolo suministrado por Agdia Inc. utilizando anticuerpo de captura anti-Cymbidium mosaic virus (CymMV 1:200 v/v CAB 89500) y el anticuerpo anti-ratón para CymMV conjugado con fostatasa alcalina producido en conejo (1:200 v/v ECA 89500), los controles positivos (CymMV, Agdia Inc.) y negativos (hojas sanas Agdia Inc.). En la evaluación de resultados se utilizó el lector de densidad óptica o espectro para microplacas de ELISA (LabSystems Multiskan); para cada muestra se consideraron los valores obtenidos en las lecturas así positivas cuyo valor de absorbancia a $405 \mathrm{~nm}$ fue mayor al valor del control negativo. Negativas cuando el valor de absorbancia a $405 \mathrm{~nm}$ fue menor o igual al control negativo, se utilizaron placas de fondo plano tipo Immunolon 2B (Dynex Technologies, Estados Unidos).

Para la detección de Odontoglossum ringspot Virus se siguió el protocolo ELISA suministrado por Agdia Inc. utilizando anticuerpo de captura anti-Odontoglossum ringspot virus (ORSV 1:200 v/v $\mathrm{CAB} 54300)$ y anticuerpo anti-Odontoglossum conjugado con fostatasa alcalina (1:200 v/v ECA 54300), ambas producido en conejo. Los controles positivos (ORSV, Agdia Inc.) y negativos (hojas sanas Agdia Inc.). Para la evaluación de resultados se utilizó el lector de densidad óptica o espectro para microplacas de ELISA. 


\section{RESULTADOS Y DISCUSIONES}

La evaluación de los iniciadores seleccionados para la detección de los virus, CymMV y ORSV, se realizó en muestras que presentaron señales clínicas; hojas, flores y bulbos. Para el análisis de resultados se realizó la migración de los productos para el virus CymMV en gel de agarosa cuyos resultados se muestran en la Fig. 1. Los productos migrados en gel de Agarosa para el virus de ORSV son ilustrados en la Fig. 2.

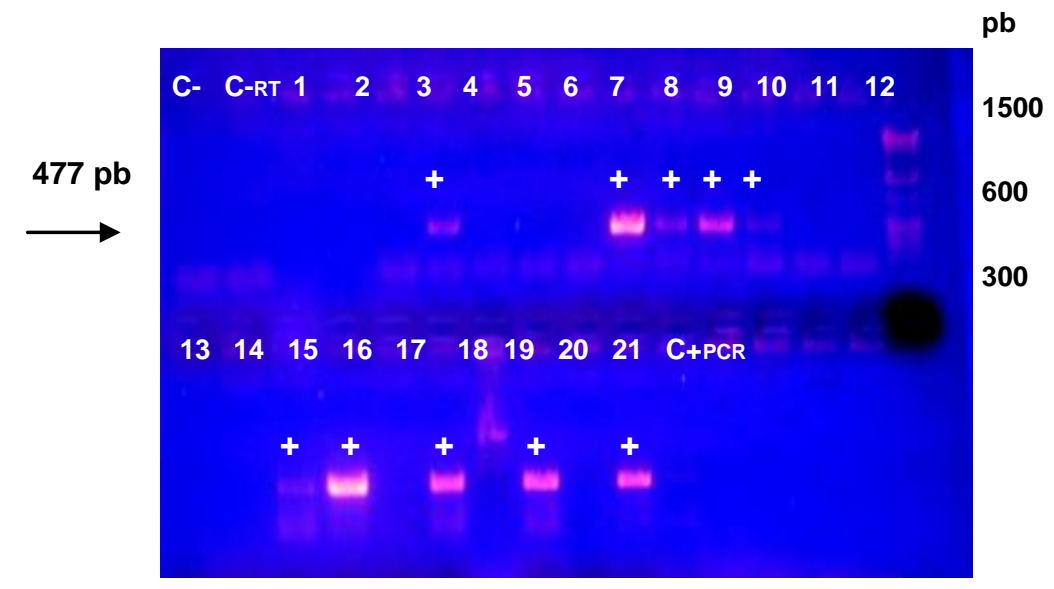

Figura 1. Detección por RT-PCR del ARN viral de CymMV. Fila 1-3 Muestras de hojas totalmente sanas; Fila 5-6 muestras de flores con apariencia viral; Fila 4, 8-14 hojas con señales clínicas; Fila 15 y 18 muestras de bulbos con señales clínicas; Fila 16, 17, 19-21 muestras de hojas con señales clínicas; MPM marcador de peso molecular; pb pares de base, los números a la derecha corresponden a la escala del marcador de peso molecular. La flecha de la izquierda indica el tamaño del fragmento de 757 pb obtenido en este trabajo, correspondiente al ARN viral de CymMV.



Figura 2. Detección por RT-PCR del ARN viral de ORSV.Fila 1-3: Muestras de hojas totalmente sanas, Fila 5-7: muestras de flores con señales clínicas, Fila 4, 8-14: hojas con señales clínicas, Fila 15 y 18: muestras de bulbos con señales clínicas, Fila 16, 17, 19-21: muestras de hojas con señales clínicas, MPM: marcador de peso molecular, pb: pares de base, los números a la derecha corresponden a la escala del marcador de peso molecular. La flecha de la izquierda indica el tamaño del fragmento de $477 \mathrm{pb}$ obtenido en este trabajo, correspondiente al ARN viral de Odontoglossum ringspot virus. 
Los protocolos de extracción de ARN viral, los parámetros de PCR y los primers seleccionados permitieron obtener productos de PCR de tamaño específico para cada uno de los virus en muestras con sintomatología de presunción. Los resultados confirman la presencia de los virus, con un amplicón de $757 \mathrm{pb}$ que corresponde al virus de Cymbidium mosaic virus y un amplicón de $477 \mathrm{pb}$ correspondiente a Odontoglossum ringspot virus. La flor positiva para CymMV presentó mosaico en los pétalos y la muestra de hoja positiva para el ORSV tenía manchas circulares necróticas. Las otras muestras, a pesar de presentar sintomatologías de infección, no resultaron positivas. Sin embargo, no se descarta que pudieran haber sido positivas para el virus no analizado, o que la infección fuese de otro origen.

La segunda etapa correspondió al análisis de muestras sintomáticas y asintomáticas mediante PCR y ELISA en la que se evaluó la capacidad de detección por ambas técnicas; el material seleccionado corresponde a muestras de diferentes órganos (hojas, flores, bulbos) de diferentes plantas con el objetivo de valorar si la detección es posible en cualquier muestra, además se utilizaron hojas de plantas aparentemente sanas para verificar su sanidad. Las diferentes muestras presentan señales clínicas de infección viral. Para determinar si las muestras presentan los virus CymMV y ORSV en los diferentes órganos de la planta mediante RT-PCR, se realizó la extracción de ARN viral y los productos fueron migrados en gel de agarosa, los resultados se muestran en la Figs. 1 y 2 (RT-PCR) y la Fig. 3 (ELISA).

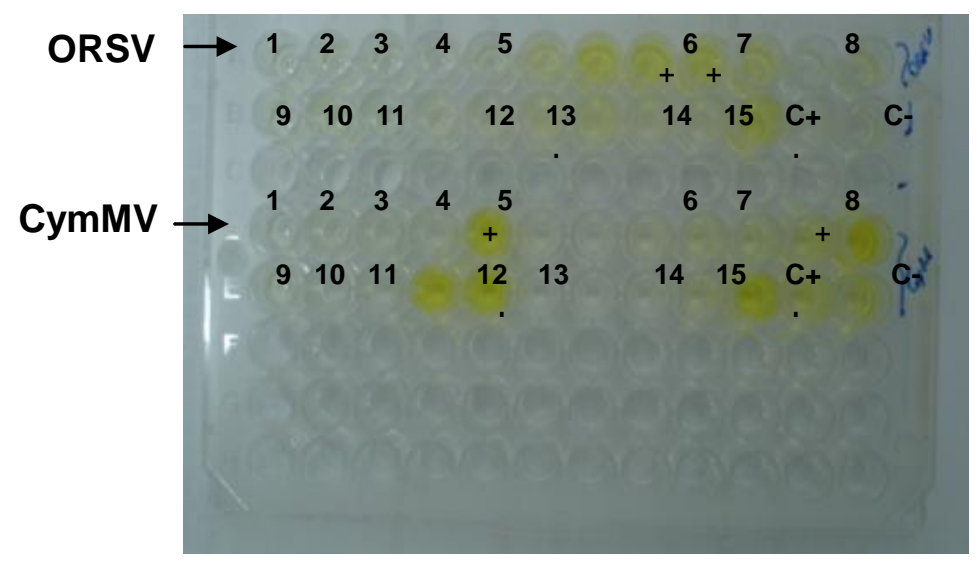

Figura 3. Diagnóstico ORSV y CymMV mediante ELISA. Parte superior: Fila 1-3 muestras de hojas totalmente sanas; Fila 5 muestra de flor con señales clínicas; Fila 4, 6-10 hojas con señales clínicas; Fila 11 y 13 muestras de bulbos con señales clínicas; Fila 12, 14, 15 muestras de hojas con señales clínicas. Las filas correspondientes a la parte inferior corresponden al diagnóstico del virus CymMV distribuídas de la misma forma que para el virus ORSV.

Tabla 1. Resultados obtenidos en muestras de diferentes órganos aplicando RT-PCR y ELISA.

\begin{tabular}{|c|c|c|c|c|c|c|c|c|c|c|c|}
\hline \multirow[b]{2}{*}{ Plantas } & \multirow[b]{2}{*}{$\begin{array}{c}\text { Tipo } \\
\text { muestra }\end{array}$} & \multicolumn{5}{|c|}{ Análisis RT-PCR } & \multicolumn{5}{|c|}{ Análisis ELISA } \\
\hline & & $\begin{array}{c}\text { Cym } \\
\text { MV } \\
+\end{array}$ & $\begin{array}{c}\text { Cym } \\
\text { MV } \\
-\end{array}$ & $\begin{array}{c}\text { ORS } \\
\mathrm{V}+\end{array}$ & $\begin{array}{c}\text { ORS } \\
\text { V - }\end{array}$ & $\begin{array}{c}\text { Cym } \\
\text { MV/ } \\
\text { ORS } \\
\text { V }\end{array}$ & $\begin{array}{c}\text { Cym } \\
\text { MV } \\
+\end{array}$ & $\begin{array}{c}\text { Cym } \\
\text { MV } \\
-\end{array}$ & $\begin{array}{c}\text { ORS } \\
\mathrm{V}+\end{array}$ & $\begin{array}{l}\text { ORS } \\
\text { V - }\end{array}$ & $\begin{array}{c}\text { Cym } \\
\text { MV/ } \\
\text { ORS } \\
\text { V }\end{array}$ \\
\hline \multirow{3}{*}{3 sanas } & Hojas & 0 & 3 & 0 & 3 & 0 & 0 & 3 & 0 & 3 & 0 \\
\hline & Total & 0 & 3 & 0 & 3 & 0 & 0 & 3 & 0 & 3 & 0 \\
\hline & Hojas & 5 & 7 & 5 & 7 & 3 & 5 & 9 & 3 & 11 & 1 \\
\hline \multirow{3}{*}{$\begin{array}{c}18 \\
\text { sintomática }\end{array}$} & Flores & 3 & 0 & 0 & 3 & 0 & 3 & 0 & 0 & 3 & 0 \\
\hline & Bulbos & 0 & 1 & 1 & 0 & 1 & 0 & 2 & 1 & 1 & 0 \\
\hline & Total & 8 & 8 & 6 & 10 & 4 & 8 & 11 & 4 & 15 & 1 \\
\hline
\end{tabular}


La microplaca ELISA exhibe los resultados producto de los extractos depositados en los posos. La coloración intensa amarilla corresponde a las muestras que resultaron positivas para los virus. Se observan 3 muestras positivas para CymMV ( 2 hojas con señales clínicas y 1 flor) y 3 positivas para ORSV ( 2 hojas con señales clínicas y 1 bulbo). No se registró muestras contaminadas por ambos virus. Los controles positivos para ELISA correspondieron a hojas de Cymbidium contaminados con los dos virus, éstos siempre se manifestaron positivos. Del análisis de muestras utilizando las dos técnicas se obtuvo los siguientes resultados (Tabla 1). La detección del ORSV por RT-PCR resultó más eficiente ya que 6 plantas (60\%) fueron positivas contra 4 (40\%) mediante la palicación del ELISA.

Las 3 plantas de las cuales se tomaron muestras de hojas sanas resultaron ser 100\% negativas para ambos virus por ambas técnicas empleadas. De las 18 plantas con señales clínicas se pudo detectar por RT-PCR, un 27,8\% de hojas, un 16,7\% de flores positivas para CymMV; así mismo se detectó un $27,8 \%$ de hojas, un 5,6\% de bulbos positivos para ORSV y no se detectó muestras positivas de flores. También se pudo detectar un $16,7 \%$ de hojas y un 5,6\% de bulbos con infecciones combinadas (ver Fig. 4).

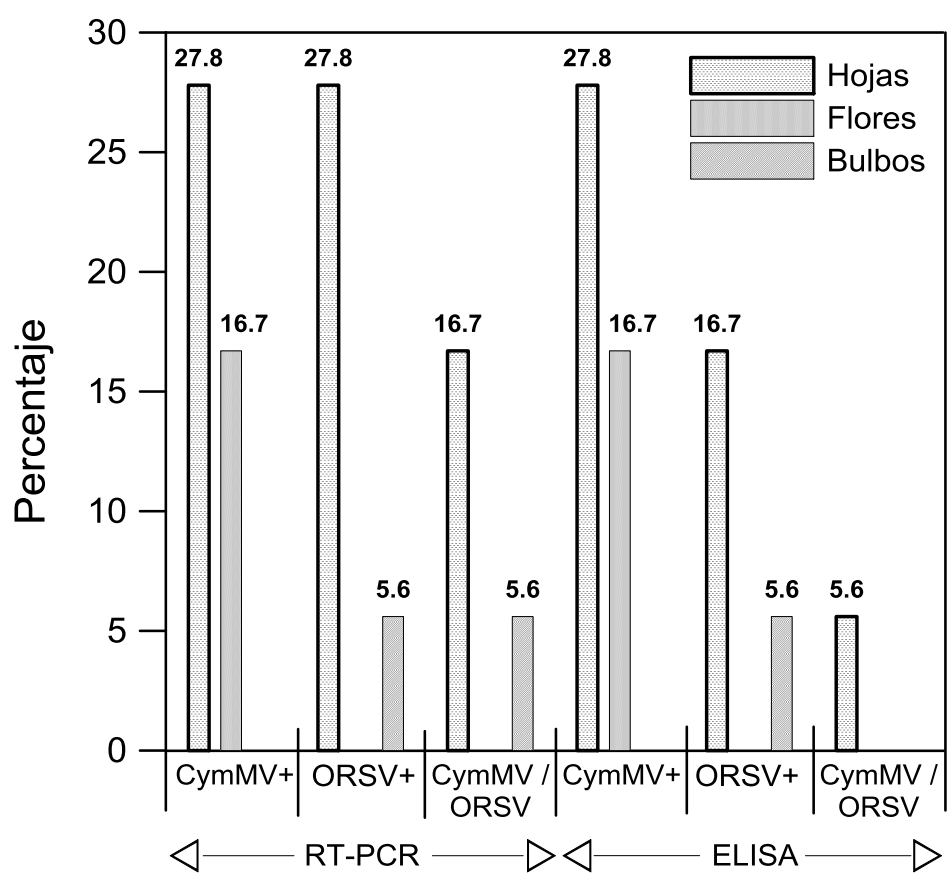

Figura 4. Número de muestras y \% respectivos que dieron positivo para ambos virus tanto para hojas, flores, bulbos, evaluados por RT-PCR y ELISA.

Con ELISA, se obtuvo el mismo resultado que la RT-PCR para la detección del CymMV, excepto que el bulbo con doble infección no salió positivo. El virus ORSV fue detectado solo en 4 hojas de las 6 positivas por RT-PCR, y 1 bulbo de los 2 positivos. Una sola planta resultó positiva por ELISA contra 4 positivas por RT-PCR.

La técnica RT-PCR pudo detectar exitosamente la presencia de ambos virus en los diferentes órganos de las plantas al igual que utilizando la técnica ELISA; sin embargo, hay diferencias entre las dos técnicas. En un contexto general, se ve que de las 23 muestras evaluadas por ambas técnicas un $34,8 \%$ de las muestras son positivas para CymMV por RT-PCR y ELISA (Fig. 5). Mientras que para la detección de ORSV 26,1\% de muestras son positivas por RT-PCR, de las cuales solo un 17,4\% son detectadas positivas por ELISA, lo cual corresponde a un 8,7\% más de detección mediante RT-PCR. Por RT-PCR se detecta un $17,4 \%$ de muestras con infecciones combinadas a diferencia de ELISA en la cual solo se detecta un 4,3\%, siendo un $13 \%$ más de detección por RT-PCR, esto podría deberse a la carga viral presente en las muestras en el momento que son analizadas, debido a que RT-PCR detecta mínimas cantidades de ARN viral. En éste ensayo con RT-PCR se pudo detectar la presencia simultánea de ambos virus, con ELISA esta detección se vió limitada. 


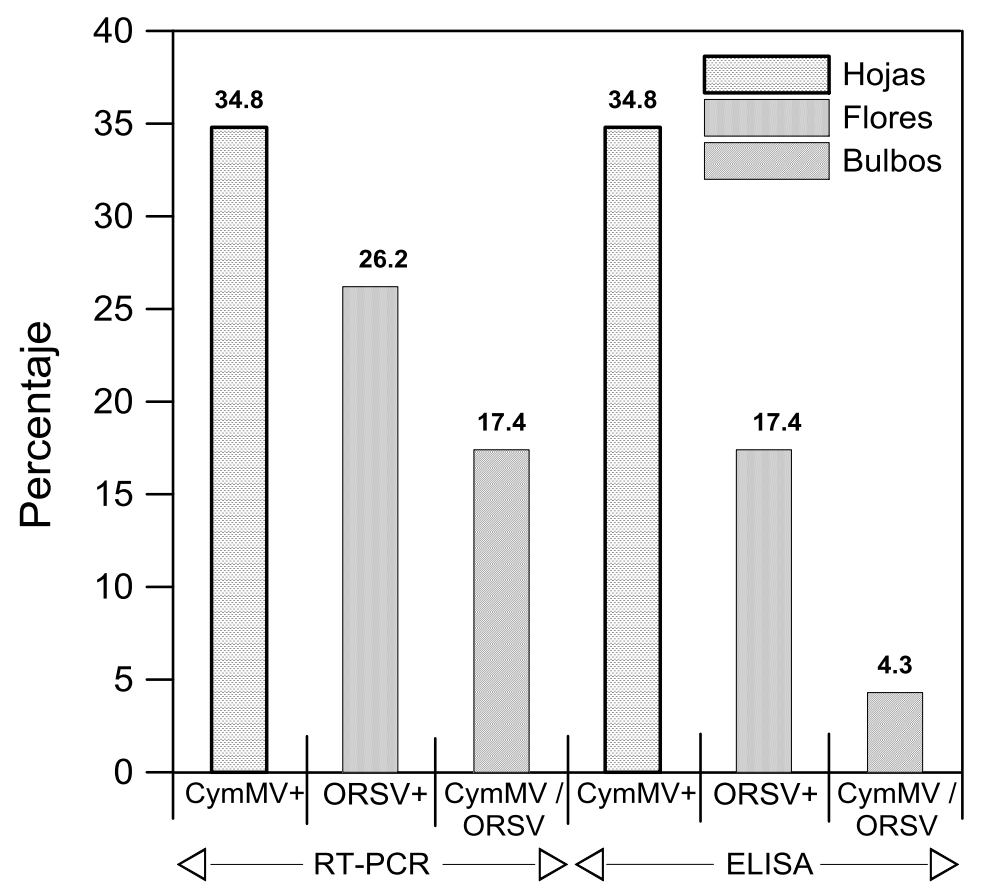

Figura 5. Gráfico de porcentajes de muestras que dieron positivo en el diagnóstico de virus CymMV y ORSV mediante RT-PCR y ELISA.

Algo interesante de observar en cuanto a la detección de CymMV tanto por RT-PCR así como ELISA, es que la mejor muestra para la detección de este virus, serían las muestras de flores ya que de 3 muestras evaluadas todas resultaron positivas, a diferencia de cuando se utilizan hojas, en las cuales solo 5 de un grupo de 15 muestras salieron positivas, en los bulbos no pudo ser detectado. Mientras que para la detección de ORSV los bulbos podrían ser las mejores muestras ya que de 2 bulbos evaluados por RT-PCR fueron detectados en ambos (ORSV 1 detectado de forma simple, y el otro en infección combinada), mientras que por ELISA solo fue detectado únicamente en 1 bulbo (detección simple), seguido por las hojas en las cuales se detectó en 5 por RT-PCR y 3 por ELISA, en las flores no pudo ser detectado este virus. La eficiencia de la RT-PCR fue similar, 1,5 y 4 veces mayor con respecto a ELISA para la detección de CymMV solo, ORSV solo y CymMV/ORSV combinados, respectivamente.

La tercera etapa correspondió a la evaluación de material micropropagado a partir de plantas infectadas con CymMV a través del diagnóstico por RT-PCR y ELISA a plantas adultas madre con sus respectivas plántulas hijas (0,5-1 cm tamaño), extraídas vía meristemo cuyo objetivo es la indexación de material vegetativo. De la planta madre escogida que presentó clorosis a nivel foliar. Se evaluaron 18 muestras de plántulas (de 0,5-3 cm alto) tanto de aquellas que presentaron señales clínicas, otras un ligero amarillamiento y otras que no presentaron señales clínicas utilizando las dos técnicas RT-PCR y ELISA.

Los resultados demuestran que de un grupo de 19 muestras (1 hoja y 18 plántulas) seleccionadas 1 hoja y 10 plántulas son positivas por RT-PCR para CymMV, mientras que por ELISA se confirma la misma hoja, pero solo 6 plántulas son positivas.

Cuando se micropropaga a partir de una planta madre que es diagnosticada positiva para CymMV, un 55,6\% de las plántulas hijas fueron detectadas positivas por RT-PCR, mientras que si se emplea la técnica ELISA en el proceso de certificación solo se detectó un 33,3\% positivas, por lo cual la técnica de RT-PCR detectaría un 22,2\% más muestras positivas en muestras microrpopagadas a partir de material infectado. La eficiencia de la RT-PCR frente al ELISA fue de 1,7 veces mayor en las plántulas mientras que para las hojas fue similar. 
Al no conocer el nivel de sensibilidad de la detección del virus mediante la RT-PCR no se puede garantizar que las plántulas negativas están exentas de virus. La RT-PCR es una técnica rápida y confiable para la detección de virus en protocormos de gladiolos en donde los virus persisten en forma latente o en una muy baja concentración y éstos no son detectables por métodos serológicos convencionales, sin embargo existen técnicas mucho más sensibles que la RT-PCR, como son: la RTnested-PCR o la Real-time PCR que permite cuantificar absolutamente el producto amplificado.

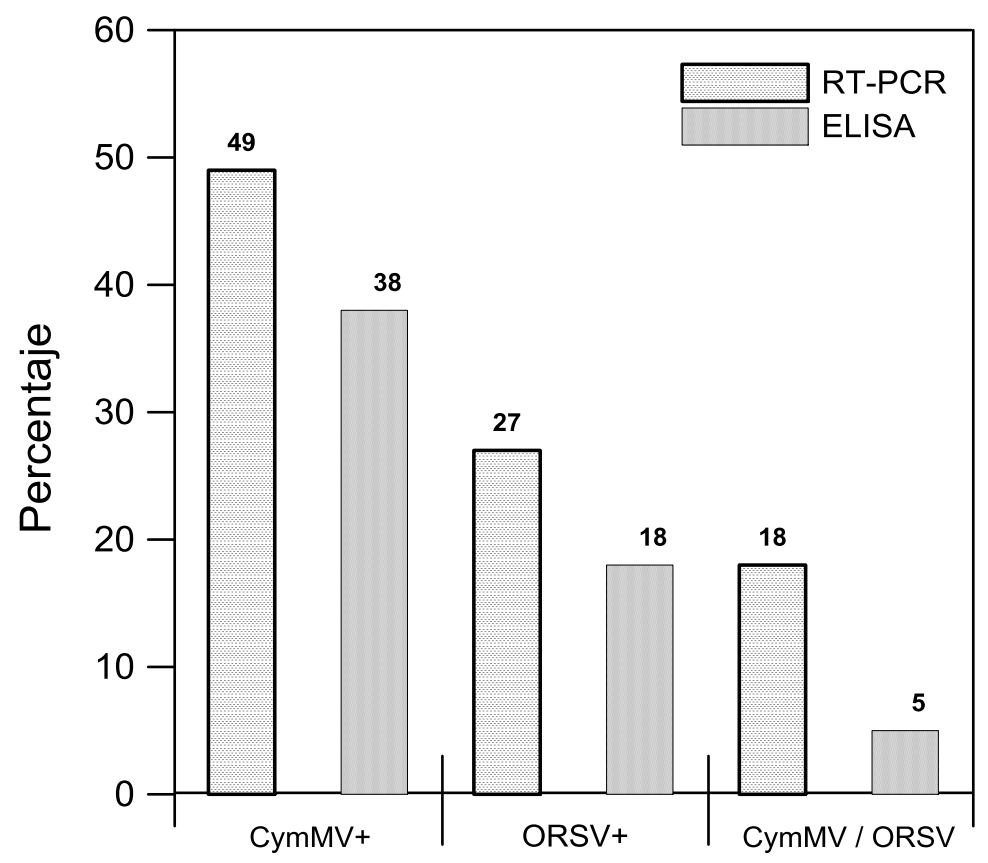

Figura 6. Gráfico comparativo de las dos técnicas RT-PCR y ELISA de todo el experimento.

La cuarta etapa (ver la Fig. 6) correspondió al análisis comparativo de los resultados de RT-PCR y ELISA. En términos generales de análisis, podemos observar que de 39 muestras analizadas para CymMV, mediante RT-PCR se pudo detectar un $49 \%$ de muestras positivas, mientras que por ELISA solo se detectó un 38\%. De 22 muestras evaluadas para ORSV se detectó por RT-PCR un 27\% y por ELISA un 18\%; así mismo de estas 22 muestras se pudo detectar por RT-PCR un 18\% de muestras con infección combinada, mientras que por ELISA solo fue de un 5\%. Esto nos demuestra que la RTPCR tiene una eficiencia de detección de 1,3 y 1,5 veces más que ELISA, a la vez que es 4 veces más eficiente en detecciones combinadas.

En la quinta etapa se evaluó a insectos posibles vectores de virus. Investigaciones anteriores señalan que no existen vectores conocidos para el virus de CymMV y ORSV. Se analizó 4 tipos de insectos que encontramos en la plantación de orquídeas, en plantas ornamentales y frutales cercanos al invernadero de crecimiento de los cultivos (tipo áfidos, arañitas, Trips, arañitas verdes). Para la extracción de proteínas se utilizó el protocolo proveído por Concepto Azul cuyos resultados dieron negativo en todos los casos, con lo cual podemos confirmar que las plagas presentes en las plantaciones de orquídeas áfidos, arañitas, trips no son vectores del virus CymMV y ORSV.

Los síntomas foliares (ver Figs. 7 y 8) observados con mayor frecuencia para CymMV es clorosis en la lámina foliar (Fotografía 1) y el sobrebrotamiento fue el menos frecuente. También se observaron plantas con deformación de hojas y flores (Fotografías 3 y 7) amarillamiento (Fotografía 4). En algunos casos se presentó estriamiento (Fotografía 8), en otros casos hendiduras severas en las manchas tornándose necróticas (Fotografía 2), y en otros casos bandeados cloróticos, esto a nivel foliar y en bulbos; en las flores se manifestó muy significativamente el mosaico en pétalos y sépalos acompañado de una necrosis precoz (Fotografías 6 y 7), siendo el menos frecuente la deformación de la simetría floral. 


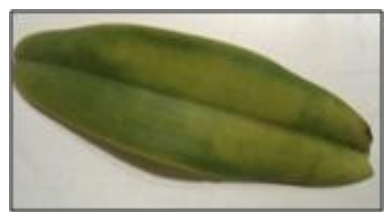

1. Clorosis foliar.

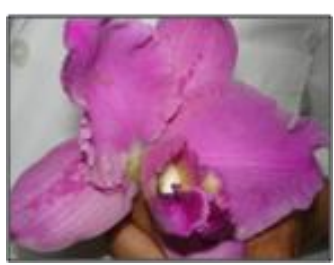

6. Mosaico y necrosis precoz.



2. Clorosis y mancha hendida necrótica.

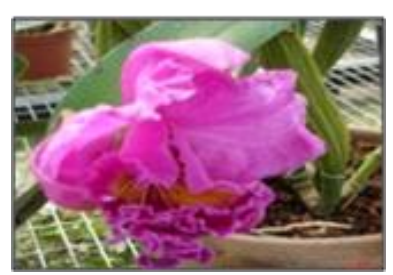

7. Deformación simetría floral.

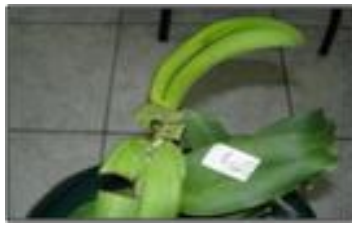

3. Deformación de hojas.



8. Bandeado clorótico.

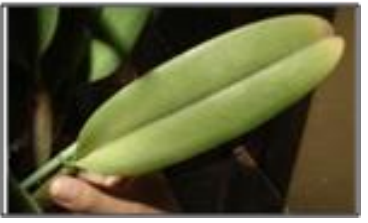

4. Amarillamiento foliar.

Figura 7. Fotografías que indican los síntomas que ocasiona CymMV.

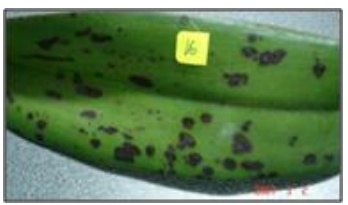

9. Manchas anilladas.

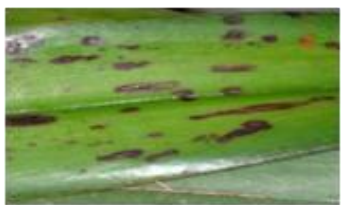

10. Patrones lineales necróticos.

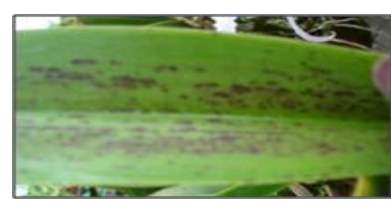

11. Punteado necrótico.



12. Bulbo con manchas necróticas anilladas.

Figura 8. Fotografías que indican los síntomas que ocasiona ORSV.

Los síntomas observados para plantas infectadas con ORSV son: manchas anilladas necróticas, punteado necrótico en la lámina foliar y en bulbos, bandeado clorótico. El ORSV no fue detectado a nivel de flor lo que indica que el tropismo del ORSV fue mayor en hojas y bulbos (Fotografías 9 y 12). Los síntomas foliares observado con mayor frecuencia para ORSV son las manchas anilladas necróticas (Fotografía 9), el punteado necrótico (Fotografía 11), el bandeado clorótico fue el menos frecuente. También se observaron plantas con patrones lineales que inicialmente son cloróticos y finalmente se tornan necróticos (Fotografía 10). En el presente trabajo no se obtuvieron flores con la presencia de ORSV.

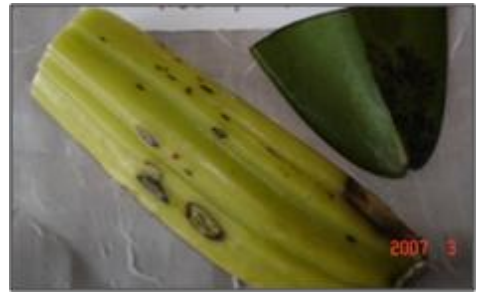

13. Manchas hendidas anilladas necróticas. Clorosis en bulbo.



14. Manchas hendidas necróticas, clorosis, punteado necrótico.

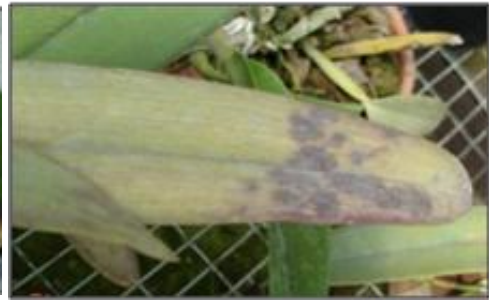

15. Clorosis, manchas anillada.

Figura 9. Fotografías que indican los síntomas que ocasionan CymMV y ORSV. 
En el caso de muestras que presentaban el ataque de los dos virus tanto CymMV como ORSV presentaron características de los dos virus, siendo posible la identificación con la ayuda de metodologías moleculares.

En la Fig. 9 podemos apreciar la combinación de los síntomas de los dos virus (Fotografías 13 a 15). En muestras que presentaron el ataque de los dos virus al mismo tiempo, las señales clínicas se manifestaron con clorosis, manchas hendidas, punteadas, profundas y necróticas, en consecuencia un ataque severo.

\section{CONCLUSIONES}

Los primers utilizados para detectar el ARN viral de CymMV y ORSV permitieron la obtención de un fragmento específico del genoma con757 y $477 \mathrm{pb}$, respectivamente. Se comprobó la presencia de ARN virales tanto de CymMV y ORSV en especies de catleyas de interés comercial por las dos técnicas RT-PCR y ELISA, utilizando diferentes tejidos infectados (hojas, flor, bulbos, plántulas). El virus fue exitosamente detectable por RT-PCR en muestras de plantas con señales visibles y también en aquellas en donde las señales clínicas eran leves. Los resultados obtenidos mostraron que la técnica de RT-PCR aplicada al diagnóstico de ambos virus es más sensible que el ELISA. De todas las muestras analizadas, un $49 \%$ fueron positivas para CymMV con RT-PCR, contra $38 \%$ por ELISA. El ORSV fue detectado en $27 \%$ de las muestras por RT-PCR, mientras que un $18 \%$ fueron positivas con ELISA. La RT-PCR permitió identificar $18 \%$ de muestras con doble infección mientras que por ELISA solo 5\% fueron en esta categoría. Por ende, la RT-PCR fue 1,3, 1,5 y 4 veces más eficiente para detectar infecciones por CymMV, ORSV y ambos virus respectivamente. La técnica de ELISA para CymMV parece ser más confiable que para la detección del ORSV, posiblemente por diferencias antigénicas entre los virus que fueron utilizados para la elaboración de los anticuerpos anti-ORSV. El diagnóstico de ambos virus tanto para estudios de prevalencia o incidencia en plantas silvestres, control de plantas introducidas, como para la certificación de plantas micropropagadas para fines comerciales, deberá realizarse con la técnica de RT-PCR para que el diagnóstico sea más confiable. El tropismo de los virus fue marcado, ya que el CymMV fue detectado tanto en hojas como en flores y bulbos, mientras que el virus ORSV tiende a ser identificado principalmente en hojas y bulbos y no en flores. La presencia de ambos virus en los bulbos implica una fuerte probabilidad de propagación del virus mediante procesos de micropropagación. La técnica de RT-PCR podrá ayudar a establecer metodologías que limiten la propagación de los virus, mediante tratamientos térmicos o químicos, garantizando plántulas no portadoras. Se pudo asociar características sintomatológicas con infecciones asociadas a CymMV, ORSV y a infecciones con ambos virus. Las plantas aparentemente sanas resultaron ser negativas para los diagnósticos, sin embargo, para declarar exentas de infección, se recomienda a continuación de este trabajo, evaluar la sensibilidad de detección de la RT-PCR, o implementar técnicas más sensibles como la RT-nested-PCR o la Real-time PCR.

\section{BIBLIOGRAFÍA}

Bateson, M.F., J.L. Dale, 1995. Banana bract mosaic virus: Characterization using potyvirus specific degenerate PCR primers. Arch. Virol., 140, 515-527.

Chang, C., Y-C. Chen, Y-H. Hsu, J.T. Wu, C-C. Hu, W-C. Chang, N-S. Lin, 2005. Transgenic resistance to Cymbidium mosaic virus in Dendrobium expressing the viral capsid protein gene. Transgenic Res., 14(1), 41-46.

De Blas, C., M.J. Borja, M. Saiz, J. Romero, 1994. Broad spectrum detection of cucumber mosaic virus (CMV) using the polymerase chain reaction. J. Phytopathol., 141, 323-329. 
Lawson, R.H., H.T. Hsu, 1995. Orquids, p. 409-420. In: Loebenstein, G., R.H. Lawson, A.A. Brunt (eds.). Virus and virus like diseases of bulb and flower crops. Wiley-VCH Verlag GmbH \& Co., $556 \mathrm{pp}$.

Navalinskienel, M., J. Raugalas, M. Samuitienel, 2005. Viral diseases of flower plants:16. Identification of viruses affecting orchids (Cymbidium Sw.). Biologia, 2, 29-34.

Vejaratpimol, R., C. Channuntapipat, P. Liewsaree, T. Pewnim, K. Ito, M. Lisuka, N. Minamiura, 1998. Evaluation of enzyme-linked immunosorbent assays for detection of cymbidium mosaic virus in orchids. J. Ferment. Bioeng., 86, 65-71.

Wong, S.M., P.H. Mahtani, K.C. Lee, H.H. Yu, Y. Tan, K.K. Neo, Y. Chan, M. Wu, C.G. Chng, 1997. Cymbidium mosaic potexvirus RNA: Complete nucleotide sequence and phylogenetic analysis. Arch. Virol., 142, 383-391.

Zettler, F.W., N.J. Ko, G.C. Wisler, C.G. Chang, M.S. Elliot, S.M. Wong, 1990. Viruses of orchids and their control. Plant Dis., 74, 621-626. 